\title{
Encontro OnLine CUltura LivRe do SUl: A PRODUÇÃO CULTURAL COMUNITÁRIA PARA A CONSTRUÇÃO DO COMUM
}

\author{
Beatriz Cintra Martins* \\ Universidade de São Paulo, Brasil \\ bia.martins@gmail.com \\ LEONARdo FELTRIN FoletTo** \\ Universidade Federal do Rio Grande do Sul, Brasil \\ leofoletto@gmail.com \\ Carlos Eduardo Falcão LUnA*** \\ Universidade Federal de Pernambuco, Brasil \\ carlosluna947@gmail.com
}

Recibido: Recibido 13/11/2019 / Aceptado 14/2/2020

doi: $10.26439 /$ contratexto2020.n033.4786

Resumo. Neste artigo pretendemos sistematizar a experiência de articulação em rede para o Encontro de Cultura Livre do Sul, a partir da construção coletiva do primeiro encontro, inteiramente virtual, realizado em 2018. Como método para nossa reflexão, empregamos a análise de conteúdo das mesas temáticas registradas em vídeos e a observação participante. Em nossa abordagem teórica, trazemos o debate em torno da construção dos comuns e a problematização do termo livre no atual contexto político e social da América Latina, buscando articulá-lo com o conceito de produção cultural comunitária. Em seguida, apresentamos um resumo do processo de construção do encontro e também dos temas debatidos no evento, registrando ainda o planejamento para sua continuidade. Por fim, avaliamos que o encontro favoreceu o fortalecimento do

\footnotetext{
* Doutora em Ciências da Comunicação (Universidade de São Paulo, Brasil). https://orcid.org/ 0000-00030828-2041

** Doutor em Ciências da Comunicação (Universidade Federal do Rio Grande do Sul, Brasil) https://orcid. org/0000-0003-2677-1017

*** Doutorando em Geografia (Universidade Federal de Pernambuco, Brasil). https://orcid.org/0000-00029274-3025
} 
movimento cultura livre no Sul Global, que se apresenta como uma alternativa para a construção de bens comuns da cultura a partir das diferenças e peculiaridades desses territórios e contribui ainda para mitigar suas desigualdades.

Palavras-chave: cultura livre / produção cultural comunitária / comum / Sul Global / tecnologias livres

\section{ENCUENTRO ONLINE CULTURA LIBRE DEL SUR: LA PRODUCCIÓN CULTURAL COMUNITARIA PARA LA CONSTRUCCIÓN DEL PROCOMÚN}

Resumen. En este artículo pretendemos sistematizar la experiencia de trabajo en red realizada en el Encuentro de Cultura Libre del Sur, basada en la construcción colectiva de la primera reunión, completamente virtual, celebrada en 2018. Como método para nuestra reflexión, utilizamos el análisis de contenido de los grupos temáticos grabados en video y la observación participante. En nuestro enfoque teórico, traemos el debate en torno a la construcción de bienes comunes y la problematización del término libre en el contexto político y social actual de América Latina, buscando articularlo con el concepto de producción cultural comunitaria. Luego presentamos un resumen del proceso de construcción de la reunión y de los temas discutidos en el evento, además registramos la planificación para su continuidad. Finalmente, creemos que la reunión favoreció el fortalecimiento del movimiento de cultura libre en el Sur Global, que se presenta como una alternativa para la construcción de bienes culturales comunes basados en las diferencias y peculiaridades de estos territorios y contribuye a mitigar sus desigualdades.

Palabras clave: cultura libre / producción cultural comunitaria / procomún / Sur Global / tecnologías libres 


\title{
ONLINE SOUTH FREE CULTURE MEETING: THE COMMUNITY CULTURAL PRODUCTION FOR THE CONSTRUCTION OF COMMONS
}

\begin{abstract}
In this article, we aim to systematize the networking experience for the South Free Culture Meeting, based on the collective construction of the first entirely virtual meeting held in 2018. As a method for our reflection, we used the content analysis of thematic discussion tables, recorded in videos, and participant observation. In our theoretical approach, we debated around the construction of commons, and the problematization of the free term in the current political and social context of Latin America, seeking to articulate it with the concept of community cultural production. Then, we present a summary of the meeting construction process and the topics discussed at the event, as well as its planning for continuity purposes. Finally, we believe that the meeting favored the strengthening of the free culture movement in the Global South, which presents itself as an alternative for the construction of common cultural assets based on the differences and peculiarities of these territories, and contributes to mitigate their inequalities.
\end{abstract}

Keywords: free culture / community cultural production / commons / Global South / free technologies 


\section{INTRODUÇÃO}

A articulação em rede entre coletivos que atuam numa mesma área; seja de atuação profissional, de militância ou de aproximação espacial; pode ser considerada como um dos âmbitos principais para a troca de conhecimentos, a circulação de indivíduos, grupos e metodologias, entre outras realizações conjuntas. No contexto do Sul Global, esse tipo de movimentação se faz ainda mais necessária a partir do reconhecimento da distribuição desigual dos recursos materiais e simbólicos e da divisão internacional do trabalho que relega estes países, substancialmente, a exportadores de matéria-prima e importadores de produtos de alto valor agregado, o que se reflete em diversas formas de desigualdade, entre países, entre regiões e dentro das próprias regiões.

Portanto, a atuação em rede tende a mitigar essas desigualdades ao criar as condições para a realização de ações através de complementaridades entre os grupos que se articulam. 0 caso do Encontro de Cultura Livre do Sul Global parece ser exemplar deste tipo de articulação. 0 encontro, que teve sua primeira edição realizada em dezembro de 2018, foi organizado por coletivos da Argentina, Brasil, Espanha e Uruguai e reuniu organizações e pessoas interessadas em acervos culturais, direitos na rede, comunicação e educação, entre outros temas, no âmbito da comunicação livre e da produção comunitária.

Contudo, as organizações que participaram do encontro permaneceram em contato, e continuaram realizando reuniões virtuais periodicamente, trocando experiências, divulgando as ações de cada um em seu território e trabalhando na construção da segunda edição do encontro, para a qual houve a oportunidade de participação no programa Mozilla Open Leaders'.

Além de proporcionar a articulação de diversos grupos e ativistas, o encontro procurou abordar as especificidades da cultura livre no Sul Global em relação ao Norte. Nesse sentido, a questão de fundo dos debates promovidos não foi apenas sobre as liberdades de usos e produção de tecnologias livres e sobre a livre circulação da cultura e do conhecimento, mas também, e especialmente, sobre para que e para quem são direcionadas essas tecnologias e esses bens. Outro aspecto relevante nesta abordagem foi o diálogo da cultura digital com as culturas populares locais, que tradicionalmente já operam num regime de livre circulação, além das culturas periféricas, afeitas ao compartilhamento comunitário e solidário.

1 Mozilla Open Leaders é um programa da Fundação Mozilla que oferece mentoria e assessoramento a projetos do mundo todo que buscam construir espaços abertos na internet para discussão e ação coletivas. Site: https://foundation.mozilla.org/en/opportunity/mozilla-open-leaders/ 
Assim, para pensarmos o movimento cultura livre do Sul Global e refletirmos sobre os resultados desse encontro, precisamos ir além das referências mais conhecidas sobre o tema (Lessig, 2005) e buscar uma construção teórica que possa estar mais próxima desses territórios marcados pela precariedade e desigualdade. A fim de dar mais densidade ao debate, buscamos articulá-lo com o conceito de comum (Dardot \& Laval, 2018), apoiados em alguns autores que já vêm apontando os limites das primeiras abordagens sobre cultura livre e dão conta da complexidade das realidades políticas e econômicas contemporâneas (Pasquinelli, 2012; Kleiner, 2010).

Este artigo, além de sistematizar os processos para a realização do encontro, pretende preservar a memória da articulação com potencial de servir de documentação para dinâmicas semelhantes, que teve como objetivo discutir concepções teóricas em torno da construção de comuns e da disputa em torno do termo livre pronunciado no próprio título do evento. As aproximações com o conceito de produção cultural comunitária também estão explicitadas, ainda que este conceito esteja em construção e que este espaço seja também um momento de abertura às contribuições em torno deste ferramental teórico.

Portanto, buscamos construir um esforço do particular para o geral, no sentido de debater as articulações em rede para a produção cultural na escala regional a partir de aspectos sociais e comunicacionais no contexto do Sul Global.

\section{MATERIAL E MÉTODO}

0 material coletado para a construção deste artigo foi extraído da nossa participação nos processos de organização, realização e das articulações posteriores ao Encontro de Cultura Livre do Sul Global. 0 fato de as mesas do encontro estarem disponíveis na internet, assim como os relatos das reuniões periódicas do coletivo, facilitou que se retomasse o debate das mesas. A partir desta análise de conteúdo buscamos refletir sobre as possibilidades de debate teórico em torno do fenômeno.

A realização do encontro produziu uma gama de material suficiente para que se fizesse uma pesquisa baseada no método da análise de conteúdo (Dione \& Laville, 1999, pp. 214-223), além da própria observação participante, que Pedro Demo classifica como "não apenas o envolvimento temporal do pesquisador, mas o seu pertencimento e vivência da realidade pesquisada, sem olhar externo, mas mantendo o olhar analítico inerente a sua pesquisa" (Demo, 2008, p.18). A escolha por este método foi propiciada pela participação dos autores na produção do evento como um todo e na participação como mediadores em algumas das mesas. Contudo, concomitantemente à organização do evento, a reflexão sobre as concepções teóricas que dialogaram com o tema , e ainda as similaridades e diferenças com outras formas de articulação em rede, fizeram 
com que, ao mesmo tempo, os autores se preocupassem com as questões empíricas e também com as formulações teóricas em torno do processo com o intuito de sistematizá-lo em um segundo momento, como tivemos a oportunidade de concretizar nesta publicação.

0 fato de as realizações se darem em torno de um comum consentido entre os coletivos participantes suscitou reflexões do que seriam bens e conhecimentos comuns e quais as concepções teóricas que os sustentam. Nossa análise busca suscitar também a problematização em torno do termo livre, que está em disputa entre as perspectivas da liberdade de ação, de reflexão e criação em grupo (liberdades coletivas) e a perspectiva do liberalismo econômico que em geral remete a liberdades individuais.

No âmbito da comunicação social essas tensões se complexificam a partir da confusão semântica que os usos indiscriminados do termo "livre" podem suscitar, a partir das diversas dinâmicas revigoradas por um constante fluxo de inovações comunicacionais e de mobilização das informações circulantes, além das características estéticas que estas dinâmicas produzem.

A opção pelo conceito de produção cultural comunitária visa operar por meio de uma noção que retrata aspectos das produções culturais praticadas à parte dos mercados mainstream e de nicho, e que pode abarcar a reflexão social em torno dos processos comunicacionais. Passemos então para a caracterização do objeto de estudo com o intento de detalhar os processos que introduzimos até aqui.

\section{O SENSO DE LIBERDADE E A CONSTRUÇÃO DOS COMUNS}

A ideia da cultura livre nasce inspirada pelo movimento do software livre, pelos grupos contraculturais anticopyright e pela ideia de copyleft (Torres, 2019), que mudaram as regras do que se produz, distribui e se pensa sobre software na década de 1980 . No final dos anos 1990 e início dos 2000, a cultura livre surge como um movimento de resistência ao regime de direito autoral vigente, que rege a privatização do conhecimento e da informação (Rowan, 2016). 0 Creative Commons, composto pelo conjunto de licenças baseadas no copyleft e pela organização internacional que as gerencia, surgiu em 2001 e se tornou um ator importante ao trazer mais autonomia aos autores sobre suas próprias obras, sendo uma das iniciativas que busca enfrentar o status quo do copyright e propondo uma atualização das leis relativas à propriedade intelectual a fim de adequá-las às mudanças trazidas pela tecnologia digital e pelas redes de comunicação (Baixacultura, 2017).

Em meados da década de 2000, o movimento cultura livre passa a se tornar ainda mais heterogêneo, articulando diversas iniciativas, projetos, coletivos e modos de fazer e agir que se transformaram de acordo com as mudanças das tecnologias digitais e na internet. 0 software livre e as licenças livres como as do Creative Commons continuam 
como aspectos centrais na discussão do tema, mas tópicos como a produção de conhecimento livre, a democratização da mídia ("mídia livre"), os recursos educacionais abertos (REA), os dados abertos e as práticas em prol da transparência ligadas à cultura hacker², as expressões artísticas em torno da recriação e do remix, as defesas da neutralidade da rede e da privacidade na rede, as políticas públicas de cultura de Estado (em especial, a partir dos Pontos de Cultura no Brasil; Rowan, 2016 ) e a economia colaborativa, entre outros, se tornam assuntos emergentes dentro do movimento (Baixacultura, 2017).

\section{O DEBATE SOBRE O COMUM}

Na década seguinte, a proposta do comum (procomún, em espanhol; commons, em inglês) ganha força na cultura livre como propulsora de modelos organizativos mais justos, num diálogo com a economia solidária e o cooperativismo, e ganham espaço nos laboratórios de inovação cidadã, iniciativas que surgem na Ibero-América a partir de 2012 e que foram fomentadas pela SEGIB (Secretaría General Iberoamericana ${ }^{4}$ ).

No âmbito da cultura digital, uma importante referência na discussão sobre o comum é o trabalho de Benkler (2006), que apresenta o conceito de commons como um tipo particular de arranjo institucional no qual não há uso exclusivo e cuja gestão é feita pela própria comunidade. Para este autor, commons devem significar, antes de tudo, liberdade. Assim, em sua opinião, as liberdades individuais, a democracia e a inovação têm a ganhar com a mais ampla circulação dos bens intelectuais que possibilite a maior criatividade e produção colaborativa livre entre pares (Commons Based Peer Production). Seu pensamento se alinha ao debate sobre o comum do ponto de vista liberal, cujo marco é o artigo "A tragédia dos comuns", de Hardin (1968), que analisa o uso comum de um pasto aberto por diferentes rebanhos e argumenta que é preciso haver gestão pública ou privada dos recursos comuns, caso contrário inevitavelmente ocorrerá sua depauperação.

Mais tarde, Ostrom (1990) refuta esse argumento, defendendo a autogestão como a estratégia mais eficiente. Em seus estudos sobre casos de governança de bens comuns

2 Surgida a partir dos anos 1960 nos Estados Unidos, a cultura hacker é uma subcultura que preconiza o conhecimento livre e a produção colaborativa, valoriza a liberdade, a criatividade e a autonomia. Abrange, entre outras iniciativas, o movimento software livre. Para um aprofundamento no tema, conferir Levy (2001) e Gradin (2004).

3 Os pontos de cultura foram parte de um projeto mais abrangente, implementado pelo Ministério da Cultura no Brasil, durante a década de 2000, como parte do programa Cultura Viva. 0 programa se instituiu como pontos de cultura: instituições que promoviam ações culturais a pelo menos três anos em um mesmo território, a partir de então recebia fomento para continuar suas atividades.

4 A ultima edição foi realizada em novembro de 2019 na Costa Rica. Para mais informações: https:// www.segib.org/el-6o-laboratorio-de-innovacion-ciudadana-de-iberoamerica-concluye-con10-proyectos-innovadores-a-favor-del-medio-ambiente/ 
em comunidades cooperativas como, por exemplo, o manejo da pastagem no Japão e na Suíça e os sistemas de irrigação em comunidades das Filipinas, a autora identificou práticas e critérios que favoreceram sua sustentabilidade. Seu trabalho impulsionou o florescimento de pesquisas em várias áreas do conhecimento sobre a sustentabilidade dos recursos comuns ${ }^{5}$, que não são privados nem públicos, mas partilhados por todos.

Atualmente, a discussão sobre o comum vem abrangendo cada vez mais temas pois, na medida em que o capital privado avança sobre todos os tipos de bens e muitas vezes com a anuência do poder público, esse conceito tem sido empregado, cada vez mais, para representar o contraponto daquilo que deve ser preservado: a floresta, o rio (bens naturais); a cidade (bens urbanos); o conhecimento, a cultura (bens intelectuais) etc. Não cabe neste artigo uma apresentação mais aprofundada de toda a complexidade desse debate, mas vale destacar o trabalho de alguns autores que podem dialogar com o tema do movimento cultura livre.

Em um primeiro aspecto, ressaltamos a pontuação crítica feita pelo italiano Matteo Pasquinelli (2008) ao apontar que a acepção de comum trazida por Benkler seria um tanto etérea, pois não considera que os bens imateriais estão intrinsecamente conectados à matéria, às máquinas e aos corpos que o produzem. 0 comum, argumenta, só pode ser compreendido corretamente na medida em que sejam levadas em conta todas as forças físicas envolvidas em sua produção, assim como as contradições do sistema econômico. Como um contraponto prático à visão liberal de comum representada por Benkler, Pasquinelli (2008) propõe uma noção tática de comum autônomo (autonomous commons), que pode ser esquematizada em quatro pontos:

1) allows not only passive and personal consumption but a productive use of common stock - implying commercial use by single workers; 2 ) questions the role and complicity of the commons within the global economy and places common stock out of the exploitation of large companies; 3 ) is aware of the asymmetry between immaterial and material commons and the impact of immaterial accumulation on material production (for instance IBM utilizing Linux); 4) considers the commons as an hybrid space that must be dynamically constructed and dynamically defended. (Pasquinelli, 2008, pp. 80-81)6.

De outro ponto de vista, Dardot \& Laval (2018) contribuem para aproximar o conceito

5 Por suas pesquisas com os comuns, Ostrom ganhou o prêmio Nobel de Economia em 2009, a primeira mulher a receber este prêmio. Para mais informações: http://www.elinorostrom.com/

6 Tradução dos autores: "1) permite não só o consumo passivo e pessoal, mas o uso produtivo do estoque comum - incluindo o uso comercial por trabalhadores individuais; 2) questiona o papel e a cumplicidade dos commons na economia global e estabelece o estoque de commons fora da exploração de grandes empresas; 3 ) está consciente da assimetria entre commons materiais e imateriais e o impacto da acumulação imaterial sobre a produção material (por exemplo IBM utilizando Linux); 4) considera os commons como um espaço híbrido que deve ser dinamicamente construído e defendido". 
de comum da luta política. Estes autores rejeitam a concepção essencialista do conceito e o inserem como princípio basilar para a construção de práticas sociais: "0 comum é o princípio político a partir do qual devemos construir comuns e ao qual devemos nos reportar para preservá-los, ampliá-los e lhes dar vida" (Dardot \& Laval, 2018, p. 53). Para eles, portanto, o comum é menos um recurso compartilhado e mais uma co-atividade com vistas a geração de novas formas de luta e de institucionalidades alternativas que apontem a um futuro para além das relações capitalistas de mercado.

Se, por um lado, Pasquinelli chama a atenção para as relações de poder envolvidas naquilo que à primeira vista pode parecer apenas imaterial, Dardot \& Laval pensam o comum como o próprio processo de luta contra a desigualdade e de construção coletiva de alternativas. Duas perspectivas que dialogam diretamente com a precariedade presente nos territórios do Sul Global e ajudam a pensar em formas de resistência do movimento cultura livre nesse contexto.

\title{
CRÍTICAS À CULTURA LIVRE
}

De fato, assim como o conceito de comum, o termo livre também se encontra em disputa por setores ideologicamente opostos na sociedade. A visão dada ao movimento Cultura Livre por Lessig (2005), que se tornou mais difundida, e especialmente as licenças Creative Commons, criadas por ele e outros colaboradores, receberam críticas de alguns autores (Kleiner, 2010; Cramer, 2012; Pasquinelli, 2012). Para eles, ao resguardar o princípio da propriedade intelectual com a diretriz de "alguns direitos reservados", essas licenças focam mais em garantir direitos a quem produz do que em estabelecer critérios com vistas à geração e preservação da cultura como um bem comum.

Assim, o que em tese haveria de mais subversivo no movimento, a luta contra o copyright e a favor da mais ampla circulação da cultura, poderia se transformar num meio termo customizável e mais palatável ao mercado:

\begin{abstract}
What began as a movement for the abolition of intellectual property has become a movement of customizing owners' licenses. Almost without notice, what was once a threatening movement of radicals, hackers and pirates is now the domain of reformists, revisionists, and apologists for capitalism. When capital is threatened, it co-opts its opposition. We have seen this scenario many times throughout history.... The real effect of Creative Commons is to narrow political contestation within the sphere of the already permissible. (Kleiner, 2010, p. 35) ${ }^{7}$
\end{abstract}

7 Tradução dos autores: "0 que começou como um movimento pela abolição da propriedade intelectual se tornou um movimento de personalização das licenças dos proprietários. Quase sem aviso prévio, o que antes era um movimento ameaçador de radicais, hackers e piratas, agora é domínio de reformistas, revisionistas e apologistas do capitalismo. Quando o capital é ameaçado, ele coopta sua oposição. Vimos esse cenário muitas vezes ao longo da história.... 0 efeito real do Creative Commons é restringir a contestação política dentro da esfera do já permitido." 
Outro ponto crítico enfatizado por Kleiner é que, ao não diferenciar os atores que estão em cena na produção cultural digital e a luta de classes inerente a isso, essa visão acaba favorecendo um novo tipo de exploração do trabalho adaptado à era das redes de comunicação. Desse modo, a produção compartilhada livremente no meio digital seria usada como matéria-prima por grandes empresas, sem nenhuma remuneração para seus criadores.

Desse ponto de vista, o movimento da Cultura Livre falha ao não perceber as diferenças implícitas entre a produção de software livre, que o inspirou, e a produção cultural. Enquanto a primeira garante seu sucesso comercial e a sobrevivência de seus produtores; pois é possível liberar um código e vender serviços sobre ele paralelamente; na produção de obras artísticas não existe serviço agregado a ser oferecido que compense o seu custo. Ao mesmo tempo em que defende o fim do copyright e a constituição da cultura como um patrimônio comum, o autor alerta para a necessidade de se garantir que artistas sejam remunerados por suas criações, especialmente, se outros atores estiverem fazendo uso comercial de suas obras sem oferecer nenhuma contrapartida.

Para equacionar esse problema, Kleiner propõe o conceito de licenças copyfarleft, que têm regras diferentes para classes diferentes: uma para aquelas que estão inseridas na produção coletiva e outra para quem empregue trabalho assalariado em sua produção. Aos trabalhadores seria permitido o uso, inclusive comercial, do bem comum, mas não àqueles que explorem o trabalho assalariado, que seriam obrigados a negociar o acesso. Assim, de acordo com sua proposta, seria possível preservar um estoque comum de bens culturais disponível a produtores independentes, mas ao mesmo tempo impedir sua expropriação por agentes privados.

Na mesma linha crítica, Pasquinelli (2012) lembra que Lessig, em seu livro Cultura Livre, relaciona as licenças Creative Commons com a tradição libertária anglo-americana, na qual liberdade de expressão caminha ao lado da liberdade de mercado. 0 autor italiano ressalta que o espaço dinâmico e autogerador criado pelo livre compartilhamento e recombinação de obras digitais favorece o mercado, que usa essa produção online abundante e gratuita para se expandir e criar novos monopólios e rentismos, em detrimento da constituição da cultura como um bem comum.

Para esse autor, o pensamento corrente sobre a produção no contexto das redes carece de uma reflexão mais profunda sobre os antagonismos inerentes ao capitalismo. Ele ressalta um ponto cego na cultura digital: o fato de não considerar o trabalho off-line que sustenta o mundo on-line, e suas implicações em diversas dimensões: sociais, econômicas, políticas e até mesmo ecológicas.

Como se vê, as duas críticas apontam para o viés liberal da Cultura Livre que se desenvolveu a partir dos Estados Unidos e enfatizam a importância de se proteger a produção da exploração exógena, com ênfase na construção de um patrimônio comum. 
Essas pontuações são estratégicas para se pensar as especificidades do movimento no hemisfério sul, onde a distribuição desigual de recursos materiais e imateriais é uma constante. Especialmente, a noção de comum autônomo, como um estoque comum que deve ser dinamicamente construído e defendido, pode nos ajudar a refletir sobre algumas iniciativas independentes da América Latina que participaram do Encontro Cultura Livre do Sul, e podem ser analisadas sob a luz da noção de produção cultural comunitária a ser esmiuçada a seguir.

\section{ALGUMAS APROXIMAÇÕES COM O CONCEITO DE PRODUÇÃO CULTURAL COMUNITÁRIA}

A partir das temáticas escolhidas para serem debatidos no encontro, das práticas dos coletivos participantes e da discussão em torno da construção de comuns na comunicação e na cultura, entendemos que a articulação em torno do Encontro de Cultura Livre do Sul pode ser analisada à luz do conceito de produção cultural comunitária.

0 processo de construção de produtos e experiências culturais não se dá isoladamente a partir, somente, da habilidade individual dos artistas. Ela se dá também a partir do imaginário construído coletivamente nos territórios, pela memória, vivências e contingências que a própria distribuição dos recursos nos territórios impõe. Portanto, a dimensão do comum está presente na produção cultural, pois precisa ser entendida para que se possa compreender o contexto em que a experiência cultural se concretiza.

O contexto do Sul Global também ajuda a relacionar o conceito de produção cultural comunitária ao nosso objeto de estudo, já que as contingências geradas pela distribuição desigual dos bens e das próprias oportunidades de difusão de narrativas marcam a experiência da propagação de conhecimentos comuns nesta parte do planeta. Portanto, cabe demarcar a concepção de produção cultural comunitária como

\footnotetext{
tipo de produção cultural realizado em contextos populares, geralmente em contingência material, com fortes laços de solidariedade entre indivíduos com objetivos comuns, que podem ter vínculo local ou transcender o aspecto geográfico, ao criar redes de apoio mútuo e tecnologias sociais para fazer perdurar suas narrativas. (Jesus \& Luna, 2017, pp. 61-62)
}

Ressaltamos ainda que a produção cultural comunitária tenta se diferenciar das culturas de massa e das culturas de nicho, que compartilham a característica da intermediação entre produtores e consumidores de conhecimento e cultura. Esta mediação não se dá apenas nas dimensões da forma e conteúdo, mas é especialmente problemática na dimensão da circulação da mensagem. Munidos do capital econômico, estes intermediadores (em geral, gravadoras, editoras, marchands) passam a pautar a circulação da informação na sociedade uma vez que realiza a curadoria do que é ou não veiculado. 
Seria muito pragmatismo, entretanto, fazer uma relação dual entre processos que são intermediados e os que não são, dadas as várias maneiras de mediação e da relação dialética de aproximação e distanciamento que as culturas populares e comunitárias negociam com diversas formas de mediação. A produção cultural comunitária se entranha nas diversas maneiras de propagar seus produtos e narrativas, condições difusas que a própria distribuição material desigual na sociedade ocasiona.

Portanto, a produção cultural comunitária; realizada em contextos específicos a partir do Sul Global, em relações de institucionalidade difusa, ora com relações diretas com o poder público e o mercado, ora estabelecendo redes de apoio mútuo e criando tecnologias sociais para a resolução de problemas locais; parece ser o escopo social com o qual a articulação em torno do Encontro de Cultura Livre do Sul está inserido. Isso se manifesta a partir das vivências em espaços alternativos de produção (Hackerspaces, hacklabs, telecentros), na preocupação com a produção livre, acervo e memória ou, ainda, como formação de pauta de reivindicações de políticas públicas.

\section{ENCONTRO DE CULTURA LIVRE DO SUL GLOBAL}

O Encontro de Cultura Livre do Sul foi resultado de uma construção coletiva de alguns dos grupos organizadores durante anos anteriores. Podemos recuperar a história dessa articulação em dois momentos principais: o II Congreso Internacional Cultura Libre ${ }^{8}$, realizado nos dias 30 e 31 de maio de 2013 em Quito, no Equador; e o $1^{\circ}$ Congresso Online de Gestão Cultural' (\#GCultural2016), ocorrido entre setembro e outubro de 2016 em diversos locais simultâneos e de forma on-line. Foram dois eventos em que coletivos atuantes no movimento da Cultura Livre na América Latina puderam se conhecer, trocar conhecimentos e, a partir daí, manterem contato e intercâmbios de ideias para propor ações conjuntas, entre elas o Encontro de Cultura Livre do Sul já mencionado.

O II Congresso Internacional de Cultura Livre foi realizado por uma série de entidades da América Latina, liderados pela FLACSO (Faculdade Latino-americana de Ciências Sociais) do Equador, Radialistas Apasionados ${ }^{10}$ e pela Unesco de Quito, com apoio do Ministério da Cultura do Equador. A programação trouxe debates, oficinas e conferências sobre cultura livre, gestão cultural, educação, recursos educacionais abertos e digitalização de recursos de museus e bibliotecas. Contou com a participação de coletivos, pessoas e organizações de diversos países da América Latina e Espanha. 0 objetivo do evento foi criar:

8 Mais informações em: http://baixacultura.org/a-cultura-livre-em-debate-no-equador/

9 Mais informações em: http://baixacultura.org/congresso-gcultural2016-encerramento/

10 Radialistas Apasionados y Apasionadas é uma ONG sem fins lucrativos com sede em Quito, Equador, que tem por objetivo contribuir para a democratização das comunicações, especialmente a rádio. Site: https://radialistas.net/ 
un espacio de debate e intercambio de experiencias sobre el acceso universal al conocimiento, la creación artística y cultural, la gestión de la cultura, el uso de las tecnologías abiertas y libres, la producción colectiva, el acceso abierto a producciones científicas, el uso de licencias alternativas, los nuevos modelos pedagógicos y las ventajas para la ciudadanía (Baixacultura, 2013).

A partir do Congresso, o espaço de debate e intercâmbio de experiências prosseguiu na internet, em trocas de e-mails, grupos de redes sociais e em chats. Três anos depois, após a realização de campanhas ativistas coletivas em prol da cultura livre em alguns dos países envolvidos e outras ações pontuais, uma parte dessa rede se reuniu novamente para promover o segundo evento mencionado, o Congresso Online de Gestão Cultural (\#GCultural2016). A proposta então foi a realização de um evento de debates sobre gestão cultural a partir dos princípios da cultura livre compartilhado por todos os coletivos organizadores ${ }^{11}$.

Como um evento acadêmico presencial, primeiramente, se fez uma chamada para apresentação de resumos, depois houve uma seleção das propostas apresentadas e, por fim, o debate entre os participantes. A diferença nesse caso foi que todo o processo se realizou online, inclusive a última parte, onde as pessoas debateram seus trabalhos - previamente publicados em sítios web dos coletivos organizadores do evento e coordenadores das mesas - a partir de comentários nas páginas, conversas em grupos de chat do software de mensagens instantâneas Telegram e, por fim, em videoconferências ao vivo ${ }^{12}$.

A metodologia do Congresso de Gestão Cultural Online serviu de teste para a que seria utilizada no Encontro de Cultura Livre do Sul em 2018. Diversas reuniões prévias online (através da plataforma facilitadora de conferências $\mathrm{Jitsi}^{13}$, de código aberto) foram realizadas para moldar o formato do encontro; a sistematização de cada reunião (em pads de plataformas diversas, entre elas o Riseup Pad e o Corais ${ }^{14}$ ) serviram como documento para facilitar a próxima. Diferente do Congresso \#GCultural2016, a proposta aqui era a organização de mesas de discussão online com participantes escolhidos a partir de uma curadoria de cada um dos cinco coordenadores de mesa; cada uma delas seria transmitida ao vivo, a partir das plataformas Jitsi e Google Hangouts ${ }^{15}$, sincronizadas

11 Artica Centro Cultural 2.0, Gestión Cultural (Uruguay), Comunicación Abierta (Bolívia), Aforo Gestión Cultural (México), Comandante Tom (Espanha) e BaixaCultura (Brasil). Mais informações: http:// baixacultura.org/construindo-o-primeiro-congresso-online-de-gestao-cultural/

12 Para mais detalhes das temáticas de cada uma das cinco mesas e dos procedimentos utilzados, ver http://baixacultura.org/construindo-o-primeiro-congresso-online-de-gestao-cultural/

13 Site: https://meet.jit.si

14 Site: https://www.pad.riseup.net/ e http://corais.org/

15 A discussão entre plataformas livres e proprietárias é sensível à própria questão da cultura livre, sobretudo no contexto do Sul Global. As opções por fazê-las via plataforma livre - Jitsi - e também uma plataforma proprietária - Hangouts - foi tema de discussão entre os organizadores, pois o Jitsi foi defendido justamente por ser uma plataforma livre e o Hangouts por ter mais sincronia com o YouTube. 
para transmissão nos canais do YouTube de Ártica Online/URU ${ }^{16}$ e do BaixaCultura/ BRA $^{17}$, organizadores do evento e coordenadores de mesa junto com Rede de Produtoras Culturais Colaborativas/BRA ${ }^{18}$, Ediciones de La Terraza/ARG ${ }^{19}$, Nodo Común/ESP ${ }^{20}$ e Em Rede/BRA ${ }^{21}$.

A partir das reuniões prévias de preparação e da divulgação do evento nas redes sociais e nos mailing de cada coletivo, o Encontro de Cultura Livre do Sul foi, então, realizado nos dias 21, 22 e 23 de novembro de 2018. Nesses dias, o debate ocorreu com o auxílio dos textos provocativos produzidos pelos coordenadores das mesas, publicados em suas respectivas páginas webs e também na plataforma Investigación Social.Net ${ }^{22}$, desenvolvida pelo Nodo Común. 0 debate principal, porém, foi centrado em seis mesas transmitidas ao vivo por sistema de videoconferências, tendo por tema geral as perspectivas da comunicação e da cultura livre a partir do Sul Global. A seguir, apresentamos um resumo de cada mesa:

\section{- Mesa 1: Políticas públicas e reformas legais ${ }^{23}$}

0 movimento da cultura livre nasceu em resposta ao avanço das leis de propriedade intelectual em todo o mundo. Desde então, ele questiona fortemente o papel do Estado em colocar barreiras e reprimir a livre circulação do conhecimento. Mas o movimento da cultura livre também propõe marcos normativos e políticas públicas para proteger os bens comuns, com o objetivo de socializar a produção e o acesso à cultura. Nesta mesa falaremos sobre as lutas atuais na região: reformas do direito autoral, leis de software livre e de repositórios institucionais abertos, políticas de digitalização do patrimônio e de produção cultural livre, e muitas outras propostas que vão desde a solução de problemas específicos até a mudança radical do sistema.

- Mesa 2: Digitalização e acesso ao patrimônio cultural ${ }^{24}$

Esta mesa de trabalho procura dar visibilidade às possibilidades de acesso às diversas manifestações culturais nos mais variados formatos, através de plataformas livres e que consigam lograr o alcance do público-alvo interessado

\footnotetext{
16 Disponível em: https://www.youtube.com/channel/UCaNZTjweA-mrKc9jzQ6vCFA

17 Disponível em: https://www.youtube.com/user/BaixaCultura

18 Website em: https://colaborativas.net/

19 Website em: http://edicioneslaterraza.com.ar

20 Website em: https://nodocomun.org/

21 Website em: http://www.em-rede.com/site/

22 Website: https://www.investigacionsocial.net/

23 Gravada e disponível em: https://www.youtube.com/watch?v=eKp-G2rsLn4

24 Gravada e disponível em: https://www.youtube.com/watch?v=B-P5v-YDi8k
} 
em cultura, bem como ser uma ferramenta de livre acesso para o público em geral. Na ocasião pretende-se também incluir a relação desses produtos com as licenças livres disponíveis e como reverberar os conteúdos e maneiras de salvaguardar o banco de dados para acessos futuros.

- Mesa 3: Laboratórios, hackerspaces e outros espaços de comunidades locais ${ }^{25}$ Nas últimas décadas foram criados vários tipos de espaços comunitários, como laboratórios cidadãos e hackerspaces, por todo o planeta e também no Sul Global. Com diferentes formatos e objetivos, seus participantes em geral compartilham os valores da produção colaborativa e do uso de tecnologias livres. Inseridos em diferentes contextos, mais carentes ou mais abundantes, esses espaços têm sido pólos irradiadores dos valores do conhecimento livre e da cultura livre. Mas como tem sido essa experiência? Quais suas potencialidades, limites e desafios? Essas são algumas das questões que esta mesa pretende abordar.

- Mesa 4: Redes internacionais: como nos inserimos em um movimento global? ${ }^{26}$ Para fazer e propagar a cultura livre, precisamos colaborar e tecer redes. Se somos um movimento que é contra o status quo capitalista patriarcal, de que forma podemos nos unir e tentar pequenos "hackeamentos" nesse sistema? Quem são nossos parceiros institucionais ao redor do mundo e, principalmente, no Sul Global? quais as principais redes que lutam no dia a dia pela cultura livre e o conhecimento aberto? Como fazemos para juntarmos forças e cuidarmos de nossos trabalhos, esforços e redes? Nesta mesa discutiremos como a cultura livre se insere num movimento global, quais os desafios para tecer e sustentar redes locais e globais e quem podemos contar como parceiros, institucionais e pessoais, para nossa atuação no Sul Global.

- Mesa 5: Produção cultural livre ${ }^{27}$

Cada vez mais projetos culturais decidem apostar no paradigma da cultura livre e começam, por exemplo, a usar licenças livres e casas culturais de trabalho comum, entre outras metodologias colaborativas. Um desenvolvimento conceitual muito elaborado, enquanto outros projetos têm uma sensibilidade ligada à cultura livre, mas desconhecem muitos detalhes importantes. A ideia desta mesa é mostrar diversas experiências de diferentes disciplinas culturais, aproveitando para falar sobre seus problemas relativos ao licenciamento livre, à propriedade intelectual, à constituição de catálogos ou pesquisas regionais de projetos culturais e coletivos culturais que trabalhem dentro do paradigma

25 Gravada e disponível em https://www.youtube.com/watch?v=pVpD_zzT

26 Gravada e disponível em https://www.youtube.com/watch?v=9dn_eGOXnoY

27 Gravada e disponível em: https://www.youtube.com/watch?v=8DIJnR3LKzY 
livre, entre outras questões. Um eixo transversal é como os diferentes projetos preveem a sustentabilidade.

\section{- Mesa 6: Educação aberta e cultura ${ }^{28}$}

Talvez uma das áreas mais importantes em que a cultura livre é vital para o Sul Global seja a educação, onde a necessidade de materiais educacionais acessíveis, adaptáveis e reutilizáveis é um assunto urgente para uma educação verdadeiramente democrática e equitativa. 0 movimento de educação aberta e recursos educacionais abertos é, paradoxalmente, muito importante no Norte, mas ainda não tem apoio e recursos suficientes nos países do Sul. Nesta mesa, discutiremos as práticas educacionais abertas e as políticas que foram promovidas e que devemos promover para apoiá-las, na perspectiva do Sul Global.

Mais de 200 pessoas participaram de cada uma das seis mesas e mais a de abertura ${ }^{29}$, somando no total cerca de 1000 pessoas online de 14 países diferentes do continente. Os debates trouxeram relatos das diferentes realidades encontradas na América Latina; das formas de produzir e manter um sistema livre de gerenciamento de acervos digitais a experiências de hackerspaces na América Central e no interior do Brasil; passando por um panorama das reformas das leis de direito autoral na América Latina, das iniciativas de bibliotecas e projetos digitais baseadas em tecnologias livres na educação, e dos artistas e produtores culturais que usam licenças livres para circular suas obras. Estes e outros vários projetos apresentados ajudaram a perceber a cultura livre no Sul Global como um mosaico de diferenças que tem alguns elos em comum; um deles é que a popularização das tecnologias livres precisa estar vinculada às comunidades populares como forma de empoderamento das pessoas e de diminuição das desigualdades dos países da região. Outro ponto observado no Encontro foi o de perceber a profunda diversidade das experiências como fator aglutinante para a construção de uma cultura livre que incorpore mais elementos das culturas originárias do continente, tendo assim um importante elemento de oxigenação da cultura livre enquanto movimento.

O Encontro proporcionou ainda um lampejo de renovação no movimento da Cultura Livre e também teve como resultado a escrita de um manifesto com as intenções do coletivo organizador para os próximos anos e uma proposta de pensar a cultura livre desde o Sul Global:

A discussão sobre a liberdade de usos e produção de tecnologias livres tem sido fundamental para a cultura livre desde o princípio, mas acreditamos que, no sul,

28 Gravada e disponível em: https://www.youtube.com/watch?v=VvUwN7Fu9Po

29 Contou com a participação dos coletivos organizadores das mesas e foi também lançamento da edição especial da Revista Pillku, "Amantes de la libertad". Disponível em: https://www.youtube. com/watch?v=7wXXe3HzKQY\&feature=emb_title 
temos a urgência maior de nos perguntar para quê e a quem servem nossas tecnologias livres. Não basta somente discutir se vamos usar ferramentas produzidas em softwares livres ou se vamos optar por licenças livres em nossas produções culturais: necessitamos pensar em tecnologias, ferramentas e processos livres que sejam usadas para dar espaço, autonomia e respeito aos menos favorecidos, financeira e tecnologicamente, de nossos continentes, e para diminuir as desigualdades sociais em nossos locais, desigualdades estas ainda mais visíveis no contexto de ascensão fascista global que vivemos nesse 2018. (Baixacultura, 2018, párr. 3)

Após o evento, as organizações que articularam o encontro passaram então a planejar a segunda edição, desta vez com pretensões de realizá-la também de forma presencial, mas sem esquecer a metodologia online na intenção de não abandonar o caráter acessível e aberto que a transmissão proporciona. Movidos por este intuito, o coletivo organizador foi contemplado pelo já citado programa Mozilla Open Leaders, promovido pela Mozilla Foundation, com a missão de aprender e compartilhar ferramentas, oferecer orientações e ajudar no desenvolvimento de projeto nos próximos anos.

Após seis meses de mentoria e participação numa rede global de pessoas e projetos ligados à comunidade Mozilla, determinamos algumas metas e caminhos para os próximos anos, como descrito no Manifesto de Cultura Livre do Sul Global já citado: realizar encontros bianuais para nos juntarmos em defesa da cultura livre e dos bens comuns; criar e manter espaços online para fomentar o debate e os intercâmbios entre os diferentes projetos e atores da cultura livre do Sul; alimentar e divulgar mais amplamente as plataformas para mapeamento e curadoria de iniciativas de cultura livre; propor formações contínuas em cultura livre, para relacionar as práticas e os conceitos com as pessoas e projetos do Sul Global; promover espaços seguros de inclusão e diversidade dentro dos debates da cultura livre, garantindo a igualdade de direitos ${ }^{30}$ (Baixacultura, 2018).

Sabemos, no entanto, que a construção de uma rede que articule a produção cultural comunitária nesta região do planeta está para além dos três dias de Encontro de Cultura Livre do Sul Global. Em torno do que foi discutido na seção teórica, acreditamos que seja possível elencar as relações do Encontro com a construção de comuns, com o compartilhamento de ferramentas livres de produção e distribuição de artefatos culturais, com a articulação em rede e com a produção cultural realizada "de baixo pra cima" com o protagonismo de artistas periféricos em seus países e com relação à produção cultural no mundo.

30 Acrescentamos, ainda, mais três objetivos durante o Mozilla Open Leaders: fortalecer a liberdade de expressão, a liberdade de acesso à informação e a acessibilidade à criação de espaços democráticos de comunicação que garantam avanços nas discussões sobre cultura livre e na construção democrática de políticas sobre o tema. 
A contribuição do Encontro para a construção de comuns foi o compartilhamento de experiências de diversos países do Sul Global, permitindo a identificação de contingências e de objetivos e desejos em comum, aglutinando atores sociais geograficamente distantes, mas em contextos sócio-culturais equivalentes. No que concerne ao compartiIhamento de ferramentas livres, o Encontro em si foi um exercício para experimentá-las, como no caso do uso do Jitsi para reuniões e conferências, e de compartilhar experiências de espaços, ferramentas e plataformas livres que podem ser reaplicadas em contextos semelhantes, propiciando condições para a maior obtenção de autonomia por parte dos coletivos. Na perspectiva da articulação em rede, ela se faz importante para ampliar a escala do que é feito nos países, tornando os produtos e processos mais disseminados, entre os grupos. Enfim, a produção cultural comunitária, "de baixo pra cima", enquanto processo afirmativo que oferece alternativas para mercados estabelecidos de produção e difusão cultural a partir da construção dos comuns, é condizente com o que apontamos no conceito de produção cultural comunitária.

É no bojo dessas categorias de análises que o Encontro de Cultura Livre do Sul Global é parte de uma articulação que é processual, em que não se pretende que o Encontro seja um fim em si mesmo, mas que aglutine processos, saberes e ferramentas cuja apropriação pode criar as condições para mitigar as desigualdades entre os produtores de cultura do Norte e do Sul Global.

\section{CONSIDERAÇÕES FINAIS}

Este artigo teve o objetivo de propor uma reflexão teórico-metodológica para articulação em rede, a partir da sistematização do Encontro de Cultura Livre do Sul Global, desde a construção coletiva que ensejou o evento até a sua realização e perspectivas futuras. A reflexão se deu em torno das noções de construção de comuns, cultura livre e suas relações com a produção cultural comunitária. Neste sentido, cabe elencar alguns aspectos abordados neste exercício reflexivo.

As redes colaborativas são ambientes propícios para o diálogo e a análise que suscite a reflexão em torno de comuns inerentes aos anseios por solidariedade, afetividade, memória e efetivação de vivências culturais nos territórios. Somente o mapeamento dos anseios das comunidades locais é que se pode identificar as necessidades comuns de expressão e ação cultural.

Viabilizar essas ações a partir do Sul Global, onde se encontram países dependentes na divisão internacional do trabalho, é um desafio que o compartilhamento de conhecimentos pode ajudar a mitigar. Por isso a importância de ferramentas livres que não criem entraves para a livre circulação de pensamento de habilidades que possam atender as demandas dos coletivos culturais contemporâneos como gestão, acervo e comunicação, 
que tendem a facilitar não só a produção-circulação-consumo de artefatos culturais, mas também o senso de coletividade e organização.

A efetivação destes aspectos podem criar as condições para a apropriação sociotécnica e a solidariedade, suscitando uma produção cultural comunitária que possa envolver diversos setores da sociedade, como o Estado, empresariado local, artistas locais, instituições de ensino, em um movimento profícuo para experiências culturais vivenciadas "de baixo para cima", a partir das demandas locais.

A atuação em redes de circuitos curtos, redes regionais e redes das redes avançando nas escalas, pode aumentar o escopo da produção cultural comunitária e incentivar a criação de metodologias, tecnologias e experiências adequadas às demandas da contemporaneidade e protagonizada pelos sujeitos sociais de cada território. Nesse sentido, a produção cultural comunitária em rede propõe ações que incorporam as demandas do manifesto produzido a partir do Encontro de Cultura Livre do Sul de questionar para quê e a quem servem nossas tecnologias livres, bem como, de que maneira o conhecimento produzido a partir destas experiências, tenha também por foco diminuir as desigualdades sociais em nossas regiões.

Concluímos que investigar a relação com mercados de nicho, mercados mainstream e a inserção contínua de outros agentes, além dos produtores de cultura em si, como o Estado ou mesmo as empresas locais, é um desafio no qual o conceito de produção cultural comunitária pode ser uma ferramenta teórico-metodológica que auxilie em investigações futuras, pois a complexidade do tema urge por mais análises em torno de seus variados aspectos.

Nesse sentido, o movimento Cultura Livre no Sul Global, em correlação com a produção cultural comunitária, se apresenta como uma alternativa de repensar a construção de bens comuns da cultura a partir das diferenças e peculiaridades do Sul Global, região e conceito que engloba países em que questões como o combate à desigualdade de acesso à informação e cultura é fundamental. Ao proporcionar um debate aberto sobre cultura livre através de diversas perspectivas e pessoas da região e realizar ações nos territórios, o primeiro Encontro de Cultura Livre do Sul e as articulações que decorrem dele são uma pequena tentativa de combate a essas desigualdades e de unir os bens imateriais com a matéria, as máquinas e os corpos que o produzem, desfazendo a concepção das tecnologias livres como neutras e politizando-as em prol da construção dos bens comuns. 


\section{REFERÊNCIAS}

Baixacultura. (6 de abril de 2013). Construindo o primeiro congresso online de gestão cultural. Recuperado de http://baixacultura.org/construindo-o-primeiro -congresso-online-de-gestao-cultural/

Baixacultura.(21 dediciembrede 2018).CulturaLivredoSulGlobal.UmManifesto. Recuperado de http://baixacultura.org/cultura-livre-do-sul-global-um-manifesto/

Benkler, Y. (2006). The wealth of network: how social production transforms markets and freedom. New Haven: Yale University Press.

Cramer, F. (2012). 0 mal-entendido do Creative Commons. En B. Rin y A. Belisário (Org.), :()\{ Copyfight :|: Pirataria \& Cultura livre \};: (pp. 177-185). Rio de Janeiro: Beco de Azougue.

Dardot, P. \& Laval, C. (2018). Comum: ensaio sobre a revolução no século XXI. São Paulo: Boitempo.

Demo, P. (2008). Pesquisa Participante: saber pensar e intervir juntos. (2a ed.) Brasília: Liber Livro.

Dionne, J. \& Laville, C. (1999). A Construção do saber: manual de metodologia da pesquisa em ciências humanas. Belo Horizonte: Editora UFMG.

Hardin, G. (1968). The tragedy of the commons. Science, 162(3859), 1243-1248. doi: $10.1126 /$ science.162.3859.1243

Jesus, P. \& Luna, C. E. F. (Marzo de 2017). Produção Cultural Comunitária no Brasil: do empírico ao teórico. Revista Razón y Palabra, 20(495), 55-68.

Kleiner, D. (2010). The Telekommunist Manifesto. Amsterdã: Institute of Network Cultures. Recuperado de http://media.telekommunisten.net/manifesto.pdf

Lessig, L. (2005). Cultura Livre: como a grande mídia usa a tecnologia e a lei para bloquear a cultura e controlar a criatividade (trad. F. E. Costa). Trama.

Ostrom, E. (1990). Governing the commons: the evolution of institutions for collective action. Cambridge: Cambridge University Press.

Pasquinelli, M. (2012). A ideologia da cultura livre e a gramática da sabotagem. Em B. Tarin y A. Belisário (Org.), Copyfight: pirataria e cultura livre (pp. 177-185). Azougue.

Pasquinelli, M. (2008). Animal spirits: a bestiary of the commons. Rotterdam: NAi Publishers.

Torres, A. L. (2019). A tecnoutopia do software livre: uma história do projeto técnico e político do GNU. São Paulo: Alameda. 